\title{
Ein Verfahren zur quantitativen Bestimmung der Kynurensäure.
}

\author{
Von \\ Dr. Achille Capaldi aus Neapel. \\ (Aus der chemischen Abtheilung des physiologischen Instituts zu Berlin.) \\ (Der Redaction zugegangen am 8. Februar 1897.)
}

Die Kynurensäure wurde im Jahre 1853 von Liebig ${ }^{1}$ ) im Hundeharn aufgefunden. Eckhardt ${ }^{2}$ ) beobachtete, dass sie sich aus dem Harn auf Zusatz von 3-4\% Salzsäure (1,11 sp. Gewicht) abscheidet, und Zabelin ${ }^{3}$ ) benutzte diese Eigenschaft, um die Säure quantitativ zu bestimmen, er trennte sie von der gleichzeitig ausgefällten Harnsäure durch Salzsäure, in der sich die Kynurensäure löste. Auch Voit und Riederer ${ }^{4}$ ) verwenden Salzsäure, ohne aber Harnsäure und Schwefel (aus den unterschwefligsauren Salzen stammend) aus dem Niederschlage zu entfernen. Naunyn und Riess ${ }^{5}$ ) beobachteten, dass 5 cc. Salzsäure auf 100 cc. Harn nicht immer zur völligen Abscheidung der Säure genügten, und empfahlen desshalb, 10 cc. zuzusetzen, den ausgeschiedenen Schwefel entfernten sie auf mechanischem Wege; Kynurensäure und Harnsäure trennten sie durch verdünntes Ammoniak, in dem die erstere sich auflöst. Schmiedeberg und Schultzen ${ }^{6}$ ) empfehlen zur Isolirung der Kynurensäure, den Harn direkt oder nach Fällung mit Bleiacetat und Entfernung des überschüssigen Bleis durch

1) Annalen der Chemie und Pharmacie. Bd. 86, S. 125.

2) Ebenda. Bd. 97, S. 358.

3) Ebenda. II. Supplementband, S. 335, 1862 und 1863.

4) Zeitschrift für Biologie. Bd. 1, S. 315.

5) Archiv für Anatomie und Physiologie. 1869, S. 381.

6) Annalen der Chemie und Pharmacie. Bd. 164, S. 155. 
Schwefelwasserstoff auf $1 / 3$ einzudampfen, mit Salzsäure oder Salpetersäure zu versetzen, tagelang stehen zu lassen und die abgeschiedene Kynurensäure von dem Schwefel und der Harnsäure am besten durch verdünntes Ammoniak zu trennen, die ammoniakalische Lösung zur Entfernung der Farbstoffe mit Blutkohle zu behandeln, mit Essigsäure zu fällen und Lösung und Fällung mehrmals zu wiederholen. Niggeler ${ }^{1}$ ) fällte den Harn mit basischem Bleiacetat und isolirte die Kynurensäure aus dem Bleiniederschlag. Von Hofmeister ${ }^{2}$ ) wurde die Eigenschaft der Kynurensäure, mit Phosphorwolframsäure eine unlösliche Verbindung zu geben, zur Isolirung benutzt. Man versetzt eine grössere Menge Harn mit dem 10. Theil des Volumens concentrirter Salzsäure, dann mit Phosphorwolframsäure, so lange noch ein Niederschlag entsteht, filtrirt $a b$, wäscht mit verdünnter Schwefelsäure aus, presst den Niederschlag ab, zerlegt ihn in der Wärme mit Aetzbaryt. Das Filtrat wird von gelöstem Baryt durch Kohlensäure befreit, eingedampft und noch warm mit Salzsäure versetzt: es entsteht ein bräunlich gefärbter Niederschlag von Kynurensäure. Schliesslich hat Jaffé ${ }^{3}$ ) eine Methode angegeben, die darauf beruht, die Säure mittelst Alkoholextraktion zu gewinnen. Der Harn wird zum dicken Syrup eingedampft, mit heissem Alkohol extrahirt und 24 Stunden stehen gelassen; in dieser Zeit scheidet sich die Flüssigkeit klar ab, man filtrirt und wäscht den Niederschlag mit Alkohol aus. Das Filtrat wird eingedampft, der zurückbleibende Syrup in Wasser gelöst, mit verdünnter Schwefelsäure angesäuert und mit Aether stark geschüttelt. Die Kynurensäure scheidet sich ziemlich rein aus.

Die erwähnten Methoden sind bisher weder auf ihre Genauigkeit geprüft, noch mit einander verglichen worden, nur $\mathrm{Schmidt}^{3}$ ) hat zwei vergleichende Bestimmungen mittelst der Verfahren von Hofmeister und Jaffé ausgeführt und folgende S. 70 .

1) Archiv für experimentelle Pathologie und Pharmakologie. Bd. 3,

2) Diese Zeitschrift. Bd. 5, S. 67.

3) Bei Aug. Schmidt: Ueber das Verhalten einiger Chinolinderivate im Thierkörper u. s. w. Dissert. Königsberg 1884. 
Werthe, welche nicht besonders gut stimmen, erhalten. Er fand bei Benutzung von je 200 cc. desselben Harns

in dem einen Versuch nach Hofmeister 0,1984, nach Jaffé 0,1845 in dem andern Versuch $" \quad, \quad 0,1040 \quad, \quad, 0,1340$.

Für die Erforschung der noch so unklaren Bedingungen, unter denen die Bildung der Kynurensäure vor sich geht, ist es unbedingt nothwendig, eine Methode zu besitzen, deren Genauigkeit keinem Zweifel unterliegt. Auf Anregung des Herrn Professor Thierfelder unternahm ich es desshalb, diese Liicke auszufüllen und zunächst die Methoden von Schmiedeberg-Schultzen und von Jaffé zu vergleichen. Von dem Verfahren von Hofmeister sollte einstweilen abgesehen werden, da es wesentlich zeitraubender und umständlicher als die beiden andern ist. Ich benutzte zu den einzelnen Versuchen je 100 cc. kynurensäurefreien Hundeharn, dem eine bestimmte Menge reiner Kynurensäure zugefügt war. Die Ausführung. geschah in folgender Weise: 1 . Methode von SchmiedebergSchultzen. Dem zu $1 / 3$ eingedampften Harn wurde $4 \%$ conc. Salzsäure zugesetzt, der Niederschlag nach 24 Stunden abfiltrirt, getrocknet, mit Schwefelkohlenstoff und Aether gewaschen, in Ammoniak gelöst, die Lösung mit Salzsäure gefällt, der Niederschlag auf gewogenem Filter gesammelt, gewaschen, getrocknet, gewogen. 2. Methode von Jaffé. Der Harn wurde bis zur Trockne eingedampft und auf dem Wasserbad so lange mit immer neuen Portionen Alkohol extrahirt, bis das heisse Filtrat farblos abfloss. Die Extraktion liess sich auf diese Weise in kürzester Zeit zu Ende führen, man brauchte nicht 24 Stunden stehen zu lassen. Die vereinigten alkoholischen Auszüge wurden verdunstet, in Wasser gelöst und nicht mit Schwefelsäure und Aether geschüttelt, sondern nach dem Vorgange von Hauser ${ }^{1}$ ) mit concentrirter Salzsäure versetzt. Die Menge des zur Lösung benutzten Wassers betrug 1/3 der verwendeten Harnquantität, die Menge der zugefügten Salzsäure 4\%. Nach 24 Stunden wurde der Niederschlag auf gewogenem Filter gesammelt, mit Wasser, Schwefelkohlenstoff und

1) Archiv für exper. Pathologie und Pharmakologie. Bd. 36, S. 1. 
Aether gewaschen, getrocknet und gewogen (Ciolumne a der Tabelle), darauf in Ammoniak gelöst, die Lösung filtrirt, wieder mit Salzsäure gefällt, der Niederschlag in derselben Weise behandelt und schliesslich gewogen (Columne b der Tabelle). Die Resultate sind in folgender Tabelle zusammengestellt.

\begin{tabular}{|c|c|c|c|c|}
\hline \multirow{3}{*}{ 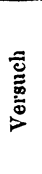 } & \multirow{3}{*}{ 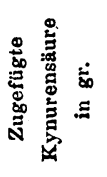 } & \multicolumn{3}{|c|}{ Wiedergefundene Kynurensäure in gr. } \\
\hline & & \multirow{2}{*}{$\begin{array}{c}\text { nach Schmiedeberg } \\
\text { Schultzen }\end{array}$} & \multicolumn{2}{|c|}{ nach Jaffé } \\
\hline & & & a & b \\
\hline 1 & 0,1200 & $0,113(=94 \%)$ & $0,128(=107 \%)$ & $0,1145(=95,4 \%)$ \\
\hline 2 & 0,1200 & $0,114(=95 \%)$ & $0,122(=102 \%)$ & $0,1170(=97,5 \%)$ \\
\hline
\end{tabular}

Die erhaltenen Resultate sprechen für die Brauchbarkeit der beiden Methoden, indessen war die gewonnene Kynurensäure stets dunkel gefärbt, ein wiederholtes Lösen und Fällen würde den Farbstoff entfernt, aber auch einen Verlust bewirkt haben. Ich richtete desshalb meine Bemühungen darauf, ein Verfahren zu finden, welches eine von Farbstoff möglichst freie Säure lieferte. Nach mehrfachem Hin- und Herprobiren fand sich in der alkalischen Chlorbariumlösung ein für meine Zwecke geeignetes Fällungsmittel. Es wurde zunächst eine Barytmischung benutzt, die aus gleichen Theilen gesättigter Chlorbaryumlösung und gesättigten Barytwassers bestand, und dem Harn das gleiche Volumen dieser Mischung zugefügt. Nach der Filtration dampfte ich ziemlich stark ein und fügte, ohne den ausgeschiedenen kohlensauren Baryt vorher zu entfernen, conc. Salzsäure hinzu. Fast sofort schied sich die Kynurensäure als weisslich röthlicher Niederschlag ab, der sich unter dem Mikroskop als aus den schönsten Krystallen zusammengesetzt erwies. Innerhalb einer halben Stunde war die Abscheidung beendet. Indessen eignete sich das Verfahren nicht zur quantitativen Bestimmung, da ein Theil der Kynurensäure alsbald als unlösliches Barytsalz ausfiel und beim Filtriren der Harnbarytmischung auf dem Filter blieb, ausser- 
dem störte die reichliche Abscheidung von Baryumcarbonat, und, wenn etwas zu weit eingeengt war, schied sich auf $\mathrm{Zu}$ satz von Salzsäure ausser der Kynurensäure auch Chlorbaryum ab. Weit besser eignete sich eine ammoniakalische Baryumchloridlösung, und zwar empfahl es sich am meisten, eine 10\% Lösung dieses Salzes, der $5 \%$ concentrirtes Ammoniak zugefügt war, zu verwenden und 2 Theile Harn mit 1 Theil dieser Flüssigkeit zu vermischen. Es blieb keine Kynurensäure auf dem Filter, der durch Salzsäure in dem concentrirten Filtrat hervorgerufene Niederschlag der Säure war rein weiss.

Um zu prüfen, welcher Grad der Concentration und welcher Salzsäurezusatz am vortheilhaftesten sei, stellte ich folgende Versuche an: 4 Portionen desselben Harns von je $100 \mathrm{cc}$. wurden in gleicher Weise mit je $50 \mathrm{cc}$. der ammoniakalischen Chlorbaryumlösung versetzt, filtrirt und eingedampft und zwar 2 auf $1 / 3$ und 2 auf $1 / 5$ des ursprünglichen Harnvolumens. Von den beiden gleich weit eingedampften Portionen erhielt die eine einen Zusatz von $2 \%$, die andere einen Zusatz von $4 \%$ concentrirter Salzsäure. Die weitere Behandlung geschah in gleicher Weise: nach 24 Stunden wurden die Niederschläge abfiltrirt, in verdünntem Ammoniak gelöst, die Filtrate (zur Entfernung des Ammoniaks) bis auf gleiches Volumen eingedampft und mit $4 \%$ Salzsäure versetzt, die ausgeschiedene Kynurensäure wurde abfiltrirt, mit Wasser gewaschen, getrocknet und gewogen. Ich führte in jedem Fall 2 Kontrollbestimmungen aus. Die Resultate finden sich in folgender Tabelle zusammengestellt.

\begin{tabular}{c|c|c|c}
\hline \hline \multicolumn{2}{c|}{ Concentration auf $1 / 3$} & \multicolumn{2}{|c}{ Concentration auf $1 / 5$} \\
\hline $2 \% \mathrm{HCl}$ & $4 \% \mathrm{HCl}$ & $2 \% \mathrm{HCl}$ & $4 \% \mathrm{HCl}$ \\
\hline 0,0330 & 0,0378 & 0,0320 & 0,0388 \\
0,0310 & 0,0376 & 0,0312 & 0,0385
\end{tabular}

Es ergibt sich, dass ein Zusatz von $2 \%$ Salzsäure nicht genügt, dass aber die Concentration auf $1 / 3$ ausreicht, denn die Unterschiede in den Kynurensäurequantitäten, welche aus 
den auf $1 / 3$ und den auf $1 / 5$ eingeengten Portionen auf Zusatz von $4 \%$ Salzsäure erhalten wurden, sind so gering, dass sie in die Fehlergrenzen fallen.

Mehrfach war mir aufgefallen, dass das Wasser, welches zum Auswaschen des Kynurensäureniederschlages diente, anhaltend sauer reagirte; es erklärt sich das offenbar dadurch, dass die Säure in Wasser wohl schwer löslich, aber durchaus nicht ganz unlöslich ist; in der That gab der Waschwasserrückstand stets die Jaffé'sche Reaktion. Um zu erfahren, ob der auf diese Weise entstehende Verlust vernachlässigt werden konnte oder nicht, wusch ich den Niederschlag in zwei Bestimmungen mehrfach mit 1 proc. Salzsäure und zum Schluss zwei Mal mit destillirtem Wasser, in zwei Kontrollbestimmungen mit destillirtem Wasser bis zum Verschwinden der Chlorreaktion. In den ersten beiden Versuchen wurden 0,0380 resp. 0,0385 gr., in den beiden andern 0,0310 resp. 0,0304 gr. Kynurensäure gefunden. Es empfiehlt sich also, das lange Auswaschen mit Wasser zu vermeiden.

Unter Berücksichtigung der gemachten Beobachtungen gestaltet sich die Ausführung meiner Methode folgendermassen.

Der Harn wird mit $50 \%$ einer 10 proc. Chlorbaryumlösung, die $5{ }^{0}{ }_{0}$ concentrirtes Ammoniak enthält, vermischt, das Filtrat bis auf $1 / 3$ der benutzten Harnmenge eingedampft und mit $4 \%$ concentrirter Salzsäure versetzt. Der Niederschlag wird nach 16 bis 24 Stunden abfiltrirt, mit 1 proc. Salzsäure ausgegewaschen, in ein Becherglas gespritzt und in Ammoniak gelöst. Die Lösung wird auf dem Wasserbad bis zum Verschwinden des freien Ammoniaks erwärmt, filtrirt und wieder mit $4 \%$ concentrirter Salzsäure versetzt. Der entstandene weisse Niederschlag wird nach etwa 6 Stunden durch gewogenes Filter filtrirt, mit 1 proc. Salzsäure und $2 \mathrm{Mal}$ mit Wasser gewaschen, bei $100^{\circ}$ getrocknet und gewogen.

Es folgen jetzt einige Bestimmungen, welche mit Hülfe dieses Verfahrens ausgeführt sind; zu Kontrollbestimmungen diente die Jaffé'sche Methode, wobei zu bemerken, dass eine Reinigung der erhaltenen Kynurensäure durch Auflösen in Ammoniak nicht vorgenommen wurde. 
1. 100 cc. Harn lieferten: mit der Methode von Jaffé 0,057 gr. und $0,0538 \mathrm{gr}$., also im Mittel 0,0554 gr., mit meiner Methode $0,0553 \mathrm{gr}$.

2. 100 cc. desselben Harns werden mit je 0,123 gr. in Ammoniak gelöster Kynurensäure versetzt, sie lieferten: mit der Methode von Jaffé $0,1810 \mathrm{gr}$. und $0,1780 \mathrm{gr}$., also im Mittel 0,1795 gr., mit meiner Methode $0,1765 \mathrm{gr}$.

Die Differenz der in den Versuchen 1 und 2 erhaltenen Werthe beträgt:

bei Benutzung der Methode von Jaffé $0,1241 \mathrm{gr}$.

bei Benutzung meiner Methode . . . 0,1212 gr.

Es sind also von der zugefügten Kynurensäure wiedergefunden: nach Jaffé 100,9\%, nach meiner Methode $98,5 \%$.

3. $100 \mathrm{cc}$. Harn lieferten : mit der Methode von Jaffé $0,0473 \mathrm{gr}$. und $0,0490 \mathrm{gr}$., im Mittel 0,0481 gr.

mit meiner Methode $0,0480 \mathrm{gr}$. und $0,0455 \mathrm{gr}$., im Mittel 0,0467 gr.

4. 100 cc. desselben Harns werden mit je 0,0624 gr. in Ammoniak gelöster Kynurensäure versetzt, sie lieferten: mit der Methode von Jaffé $0,1095 \mathrm{gr}$. und $0,1130 \mathrm{gr}$., im Mittel $0,1112 \mathrm{gr}$.

mit meiner Methode $0,1068 \mathrm{gr}$. und $0,1075 \mathrm{gr}$., im Mittel 0,1071 gr.

Die Differenz der in den Versuchen 3 und 4 erhaltenen Werthe beträgt :

bei Benutzung der Methode von Jaffé $0,0631 \mathrm{gr}$.

bei Benutzung meiner Methode . . . 0,0604 gr.

Es sind also von der zugefügten Kynurensäure wieder gefunden : nach Jaffé 101,1\%, nach meiner Methode 96,8\%.

Berücksichtigt man bei der Beurtheilung der Resultate, dass die nach meinem Verfahren gewonnene Kynurensäure rein ist, die nach Jaffé isolirte Farbstoffe enthält, welche auch durch einmaliges Umlösen in Ammoniak nicht zil entfernen sind, so wird man meiner Methode den Vorzug geben müssen, um so mehr, als sie in derselben oder in noch kïrzerer Zeit auszuführen und weniger kostspielig ist, wie jene.

Am Schluss dieser von mir über Kynurensäure ausgeführten Untersuchungen betrachte ich als angenehme Pflicht, meinem hochverehrten Lehrer, Prof. Thierfelder, für die stetige Unterstützung und Anregung meinen verbindlichsten Dank auszusprechen. 